\title{
Network dynamics, economic transition, and policy design-an introduction
}

\author{
Muhamed Kudic $^{1}$ (D) Matthias Müller ${ }^{2} \cdot$ Tobias Buchmann $^{3} \cdot$ Andreas Pyka $^{2}$. \\ Jutta Günther ${ }^{4}$
}

Received: 2 February 2021 / Accepted: 11 February 2021/ Published online: 27 March 2021

(C) The Author(s) 2021

\begin{abstract}
Network dynamics, economic transformation, and policy design are closely related phenomena that influence the performance of economic systems in a variety of ways. In this introductory paper, we set the stage for a series of excellent contributions addressing some still largely unexplored questions in this research field. At the core of our introduction, we provide a contextual structuration and classification of the contributions to this special issue. Finally, we address some contemporary issues that deserve some attention since they open up highly interesting opportunities for future research.
\end{abstract}

Keywords Network · Transition · Policy

JEL classification $\mathrm{O} 30 \cdot 033 \cdot 038 \cdot \mathrm{D} 85$

Muhamed Kudic

Muhamed.kudic@uni-siegen.de

Matthias Müller

m_mueller@uni-hohenheim.de

Tobias Buchmann

tobias.buchmann@zsw-bw.de

Andreas Pyka

a.pyka@uni-hohenheim.de

Jutta Günther

jutta.guenther@uni-bremen.de

1 University of Siegen, Siegen, Germany

2 University of Hohenheim, Stuttgart, Germany

3 Center for Solar Energy and Hydrogen Research Baden-Württemberg, Stuttgart, Germany

4 University of Bremen, Bremen, Germany 


\section{Setting the stage}

Structural change is inherent to the process of economic growth and has been a companion of economic development ever since. The structural change of modern economies is a consequence of technological progress and nowadays often named "transition". The major societal challenges of our time - such as demographic change, digitization, and climate change - are reflected in multifaceted economic transition processes. The term "transition," however, is used in a variety of ways in economic literature. It has long been applied to describe the change of entire economic systemsi.e., from a planned to a market economy (Kornai 1992). It is also used to address changes in market structure; e.g., from monopolistic to oligopolistic markets, and in business studies, transition means the restructuring inside firms.

In this special issue, we focus on technologically induced transition processes in the sense of Schumpeter's notion of creative destruction. There are countless examples in the recent past that illustrate how new technologies disrupt existing markets by replacing outdated products and services by new superior alternatives. These include, to name just a few, the replacement of analog by digital photography, the transition from the internal combustion engine to the electrical motor in the automotive industry, or the replacement of the incandescent lamp by LED lighting technology. In a nutshell, it is obvious that new technologies bear the potential to change industries dramatically.

At the same time, the pronounced complexity and dynamics of technological development processes need to be acknowledged. Today, we know that innovations are rarely the result of purely individual efforts. Empirical research shows that innovation processes are in many cases the outcome of collaborative activities of different types of actors (Wuchty et al. 2007). In many industries and technological areas, we can observe a pronounced R\&D cooperation intensity, and the emergence of innovation networks with dynamically changing compositions over time (Hagedoorn 2002; Kudic 2015; Tomasello et al. 2017). The reasons for this are manifold. R\&D cooperation offers a variety of advantages, especially in highly knowledge-intensive and volatile market environments. R\&D cooperation bears the potential of reducing risk and costs, stimulates mutual knowledge and learning processes, and increases chances for successful collective innovation processes (Hagedoorn 2002).

Individual R\&D cooperation activities at the micro level-e.g., between firms, organizations, inventors - are reflected in complex and dynamically emerging and changing network patters at higher aggregation levels. These networks can drivebut also hamper-innovation and transition processes and are themselves affected by economic and technological transition in various ways. The literature is full of empirical network studies related to issues such as network positioning and performance, both in static and in dynamic settings (Kudic 2015; Powell et al. 1996). Boschma (2005) points to the importance of geographical closeness and other dimensions of proximity. This insight particularly becomes important in innovation and research policy literature. In Europe, the so-called placed-based approach gained ground (Barca et al. 2012). The insight that the entrepreneurial activities as well as collective creation of innovation through cooperation are often specific to the local contexts led to the concept of smart specialization (Foray 2015). Fritsch $(2000,2003)$ investigates the interregional differences in innovation activities. Simulation-based network research contributed to an in-depth understanding of regularities, interaction patterns, and self- 
enforcing often non-linear processes in complex adaptive systems (Mueller et al. 2017). Tomasello et al. (2017) and Fritsch and Kudic (2021) analyze longitudinal network dynamics and determinants of systemic instabilities. Accordingly, research and development cooperation and innovation networks as well as their underlying dynamics play a central role in understanding technologically induced transition in economic systems.

Many of the abovementioned considerations are rooted in evolutionary economics thinking and inspired by the innovation system approach (Hanusch and Pyka 2007; Lundvall 1992; Nelson 1993). This approach, and later also regional, sectoral, or technological specifications of the initial idea, has only recently been used to guide and inform the design of policy interventions. The emphasis on dynamic knowledge exchange and learning process as well as the analytical distinction between organizations, linkages, and institutions inherent to the innovation system approaches has offered a solid framework for analyzing innovation networks. With the growing insights on the importance of networks of innovators, policy makers discovered this area as a subject of public support programs and intervention (Cantner et al. 2019; Günther and Meissner 2017). The implementation of policy schemes is based on the insight and identification of systemic failures (Dodgson et al. 2011; Klein Woolthuis et al. 2005; Tödtling and Trippl 2005), which would slow down or hamper innovation. Within the systemic perspective, widely unexplored innovation policy-related issues can be analyzed, which are of theoretical and applied interest.

In this respect, this special issue encourages theoretical, conceptual, and empirical research contributions on innovation networks, their structure and dynamics in the context of rapidly changing socio-economic environments, system dynamics and failures, systemic interventions, and innovation policy design.

\section{Origin and thematic scope}

The special issue has grown out of two international workshops related to the research area "networks" of the European Association for Evolutionary Political Economy (EAEPE). The 4th "network" workshop took place in November 2018 in Budapest and focused on new approaches in innovation policy design and its evaluation. This event was followed by the 5th "network" workshop in November 2019 in Stuttgart which had a focus on network dynamics and economic transition. The international workshops attracted a number of outstanding contributions addressing questions such as (i) What are the insights from innovation systems research concerning the exploration of new technological opportunities? (ii) How can we use the innovation systems perspective to govern the transformations towards sustainability? (iii) How do different types of relationships between established companies and start-up companies influence the dynamics of innovation systems? (iv) Do radical innovations influence the emergence, the development, and the composition of innovation systems and vice versa? (v) How can we identify system failures in technological, sectoral, or regional innovation systems? (vi) What can be learned from innovation systems research concerning innovation policy for rural areas? Against this backdrop, we decided to launch this special issue which was explicitly open to external submissions as well. The contributions in the special issue address two thematic fields, which are described in more detail below. 
The first thematic field revolves around the dynamics of networks with a particular focus on related transition processes of the technological field in a Schumpeterian sense. Despite the still lasting momentum of research on networks whose origins can be traced back at least to the middle of the last century, most of the early contributions has been limited to a rather static perspective. For example, the performance implications of different structural properties have been analyzed. Others emphasized that networks are prone to often radical structural change induced by both network exogenous and network endogenous effects (e.g., Hain et al. 2018). To put it differently, it is without doubt that networks spur the development of radial change and new technologies. However, on the other hand, radical change and new technologies will also always lead to considerable re-configuration of established network structures. In this respect, we see a still existing research gap for studies that analyzes the link between the dynamics of network change and economic transition processes often induced or flanked by global megatrends (e.g., digitalization, energy transition).

The second thematic field of this special issue focuses on the resulting policy implications, if we consider the co-evolution of network dynamics and economic transition processes. Despite the critique against the underlying mainstream economic reasoning (e.g., Dodgson et al. 2011), we see that "market failure" approaches are still widely used to justify policy interventions. However, any "market failure" argument will quickly reach its limits in the context of dynamic networks and systems. In addition to purely theoretical arguments, we observe in economic policy practice the increasing importance of innovation and research policy instruments. Hence, dynamic knowledge exchange, learning, and knowledge recombination processes require a stronger attention, just as it is the case in the dynamic network literature. Accordingly, the second thematic field seeks to strengthen our awareness for the urgent need to advance our theoretical understanding and justifications for policy intervention into complex dynamic systems. In line with the first thematic field, we thus draw attention to "systems failure" approach (e.g., Dodgson et al. 2011; Klein Woolthuis et al. 2005; Pyka et al. 2019). At the same time, we are also keenly interested in insights into actual funding practices that have transpired within various technology fields in recent years.

\section{Structure and content of the special issue}

The special issue consists of six research papers, organized in the two above described thematic sections. Most of them use empirical approaches to scrutinize innovation network dynamics and public innovation policy programs.

The first paper authored by Mark Knell is based on a key note lecture given at the 5th "network" workshop in Stuttgart. The paper focuses on the digital revolution and our digitalized network society and paves the way for the first thematic field. A main finding is that the digital revolution created new types of network organizations that shape our modern world. Digital innovations not only transformed the world we live in fundamentally, but also created at the 
same time new ways to organize networks within it. This is accompanied by economic growth which fosters the application of digital technologies leading to the establishment of a digital network society. The arguments by the author are inspired by works of Joseph Schumpeter, Christopher Freeman, and Carlota Perez and embedded in the literature on long waves, technological regimes, and global innovation networks.

The second paper by Mariia Shkolnykova in this special issue is insightful for at least two reasons. First, the author explores the structural network evolution in the field of plant-based biotechnology in Germany by employing two complementary datasets to explore the evolution of co-authors' and co-inventors' networks in the field during the period 1995-2015. Second, text analysis techniques are applied to gain an in-depth contextual understanding of the observed cooperation events. The analyses show significant differences in terms of knowledge advancement between science and technology networks.

This is followed by a third paper authored by Patrick Wolf and Tobias Buchmann, analyzing the development patterns in R\&D networks and technology. Their innovative approach studies the co-evolution of technology and R\&D networks using a (several) new indicator(s). The results show that this method is particularly useful for identifying structural similarities and structural changes in research and patent networks. Furthermore, the investigation of the German automotive industry indicates that changes in technology precede structural changes in the research network.

The second thematic field of the special issue (policy design) is introduced by the fourth paper written by Dominique Foray, Martin Eichler, and Michael Keller on smart specialization strategies. The paper was presented as a key note lecture given at the 4th "network" workshop in Budapest. It deals with the question how we can evaluate and further develop the European innovation and industrial policy design. It offers insights into novel approaches and perspectives for policy makers to assess smart specialization goals and support schemes. In particular, the first period of S3 implementation is analyzed to understand which policy design can truly generate valuable strategic initiatives and initiate regional transition processes.

Following this, Michael Rothgang and Bernhard Lageman dig into an important policy question in the fifth paper of this special issue: "Why are there so Few Hard Facts about the Impact of Cluster Policies in Germany? A critical review of evaluation studies". While there exist many evaluation studies, only few authors have so far taken the effort to assess these studies systematically with respect to this important question. Clusters consist of numerous network relations and are expected to generate positive effects for regional development. Thus, the paper reviews cluster policy in Germany based on empirical findings and offers a number of recommendations for policy makers.

Finally, the last paper of the special issue by Leonard Prochaska and Daniel Schiller studies the development of mission-oriented innovation policies and scrutinizes how the missions emerge, e.g. top-down or rather through an evolutionary process. It takes the example of the transition from biotechnology to bioeconomy and makes use of information from real policy programs. For the case of the transition from the narrowly defined biotechnology to the much broader bioeconomy, the authors show that the transition does not follow a linear path. 


\section{Open issues and further research avenues}

Over the past decades, a rich body of empirical literature has emerged that is highly instructive on how and why networks evolve. The same holds true for economic literature on innovation policy which has in the meantime undergone a great deal of conceptual development. Nevertheless, there are a number of reasons why we are still confronted with numerous unanswered questions to which hopefully this special issue has made a small contribution. Without any claim to completeness, a few of these reasons should be outlined below.

The evidence and the explanatory power of many empirical studies are often constrained by data limitations. The application of advanced network analysis techniques in a network evolution context requires coherent longitudinal datasets. A typical problem that arises when using secondary data or survey data relates to the intertemporal coupling of cross-sectional surveys. Due to the dynamics of companies entering and leaving the population as well as the unsteady participation behavior of the surveyed companies, at best unbalanced panel datasets subject to high fluctuations can be built up over time. If one accepts this well-known limitation of long-term survey datasets, the problem of a "clean" coupling of repeatedly appearing companies over time still remains to be solved. Events such as mergers, acquisitions, and restructurings are either completely neglected in panel data constructions or, at best, considered by using highly simplified assumptions. Measuring network change, however, opens up also several challenges. Capturing not static but dynamic structural properties of networks requires new approach and methods to describe and understand these changes. For example, while pathlength, clustering coefficient etc. are useful measures for a static analysis, in a dynamic context, we need novel indicators and criteria.

In a similar vein, the theoretical explanations of how and why actors interact and how these processes themselves can change the network topology are still rather rudimentary and simplistic. Rules, norms, and institutions, for example, are very likely to play an important role for the structuration of any socio-economic system. At the same time, also linking these network dynamics to exogenous processes such as transition processes faces the problem of causality; i.e., are changes in networks the cause or the consequence of transition processes (e.g., Orsenigo et al. 2001). All in all, a comprehensive and consistent network theory is still missing in economic literature.

The design of effective and efficient innovation policy measures requires a systemic perspective. Foray (2015) provides a well-established framework, the so-called smart specialization approach. Further related policy issues can be addressed along three analytical levels: micro, meso, and macro (Dopfer et al. 2004). On the micro level, the structure of individual decision-making and interaction among individuals has to be considered. It may be useful to think of policies that directly influence the system structures of the micro level, e.g. by strengthening conditions that are beneficial to the emergence of trust. The same holds true for the meso-level perspective. We see potential for policy-related research insights especially when it comes to the dynamics of group decision processes among different interest groups and stakeholders. In addition, Elsner $(2007,2017)$ argues that the meso level goes beyond network substructure considerations, since phenomena-such as structural or institutional emergence - should also be included here. This brings us directly to pattern formation processes at the overall network level (determined by antecedent system characteristics 
and fueled by mechanisms such as herding behavior or systematic partner selection biases). This, in turn, is directly related to systemic risks, diffusion properties, or the overall system stability and should be explicitly acknowledged when designing systemic policy measures (Bogner et al. 2018; Fritsch and Kudic 2021).

Funding Open Access funding enabled and organized by Projekt DEAL.

Open Access This article is licensed under a Creative Commons Attribution 4.0 International License, which permits use, sharing, adaptation, distribution and reproduction in any medium or format, as long as you give appropriate credit to the original author(s) and the source, provide a link to the Creative Commons licence, and indicate if changes were made. The images or other third party material in this article are included in the article's Creative Commons licence, unless indicated otherwise in a credit line to the material. If material is not included in the article's Creative Commons licence and your intended use is not permitted by statutory regulation or exceeds the permitted use, you will need to obtain permission directly from the copyright holder. To view a copy of this licence, visit http://creativecommons.org/licenses/by/4.0/.

\section{References}

Barca F, McCann P, Rodríguez-Pose A (2012) The case for regional development intervention: place-based versus place-neutral approaches. J Reg Sci 52:134-152. https://doi.org/10.1111/j.1467-9787.2011.00756. $\mathrm{x}$

Bogner K, Müller M, Schlaile MP (2018) Knowledge diffusion in formal networks: the roles of degree distribution and cognitive distance. Int J Comput Econ Econ 8:388-407

Boschma R (2005) Proximity and innovation: a critical assessment. Reg Stud 39:61-74

Cantner U, Dettmann E, Giebler A, Guenther J, Kristalova M (2019) The impact of innovation and innovation subsidies on economic development in German regions. Reg Stud 53:1284-1295. https://doi.org/10.1080/ 00343404.2019 .1639656

Dodgson M, Hughes A, Foster J, Metcalfe JS (2011) Systems thinking, market failure, and the development of innovation policy: the case of Australia. Res Policy: Policy Manag Econ Stud Sci Tech Innov 40:11451156

Dopfer K, Foster J, Potts J (2004) Micro-meso-macro. J Evol Econ 14:263-279. https://doi.org/10.1007/ s00191-004-0193-0

Elsner W (2007) Why meso? On "aggregation" and "emergence", and why and how the meso level is essential in social economics. For Soc Econ 36:1-16. https://doi.org/10.1007/s12143-007-0001-3

Elsner W (2017) Complexity economics as heterodoxy: theory and policy. J Econ Issues 51:939-978. https:// doi.org/10.1080/00213624.2017.1391570

Foray D (2015) Smart specialisation: opportunities and challenges for regional innovation policy. Regions and cities, vol 79. Routledge, London

Fritsch M (2000) Interregional differences in R\&d activities - an empirical investigation. Eur Plan Stud 8: 409-427. https://doi.org/10.1080/713666416

Fritsch M (2003) Does R\&D-cooperation behavior differ between regions? Ind Innov 10:25-39

Fritsch M, Kudic M (2021) Micro dynamics and macro stability in inventor networks. J Tech Transfer (forthcoming)

Günther J, Meissner D (2017) Clusters as innovative melting pots? - The meaning of cluster management for knowledge diffusion in clusters. J Knowl Econ 8:499-512. https://doi.org/10.1007/s13132-017-0467-z

Hagedoorn J (2002) Inter-firm R\&D partnerships: an overview of major trends and patterns since 1960. Res Policy 31:477-492. https://doi.org/10.1016/S0048-7333(01)00120-2

Hain D, Buchmann T, Kudic M, Müller M (2018) Endogenous dynamics of innovation networks in the German automotive industry: analysing structural network evolution using a stochastic actor-oriented approach. IJCEE 8:325. https://doi.org/10.1504/IJCEE.2018.096392

Hanusch H, Pyka A (2007) Principles of neo-Schumpeterian economics. Camb J Econ 31:275-289. https:// doi.org/10.1093/cje/bel018 
Klein Woolthuis R, Lankhuizen M, Gilsing V (2005) A system failure framework for innovation policy design. Technovation 25:609-619. https://doi.org/10.1016/j.technovation.2003.11.002

Kornai J (1992) The socialist system: the political economy of communism. Oxford University Press

Kudic M (2015) Innovation networks in the German laser industry. Springer, Berlin

Lundvall B-Å (ed) (1992) National systems of innovation: towards a theory of innovation and interactive learning. Pinter, London

Mueller M, Bogner K, Buchmann T, Kudic M (2017) The effect of structural disparities on knowledge diffusion in networks: an agent-based simulation model. J Econ Interac Coord 12:613-634. https://doi. org/10.1007/s11403-016-0178-8

Nelson RR (1993) National innovation systems: a comparative analysis

Orsenigo L, Pammolli F, Riccaboni M (2001) Technological change and network dynamics: lessons from the pharmaceutical industry. Res Policy 30:485-508. https://doi.org/10.1016/S0048-7333(00)00094-9

Powell WW, Koput KW, Smith-Doerr L (1996) Interorganizational collaboration and the locus of innovation: networks of learning in biotechnology. Adm Sci Q 41:116-145. https://doi.org/10.2307/2393988

Pyka A, Kudic M, Müller M (2019) Systemic interventions in regional innovation systems: entrepreneurship, knowledge accumulation and regional innovation. Reg Stud 53:1321-1332. https://oi.org/10.1080/ 00343404.2019.1566702

Tödtling F, Trippl M (2005) One size fits all?: towards a differentiated regional innovation policy approach. Res Policy 34:1203-1219. https://doi.org/10.1016/j.respol.2005.01.018

Tomasello MV, Napoletano M, Garas A, Schweitzer F (2017) The rise and fall of R\&D networks. Ind Corp Chang 26:617-646. https://doi.org/10.1093/icc/dtw041

Wuchty S, Jones BF, Uzzi B (2007) The increasing dominance of teams in production of knowledge. Science 316:1036-1039. https://doi.org/10.1126/science.1136099 